\title{
A Study on Types of Leisure Index Based on National Leisure Activities Survey 2019 in Korea
}

\author{
Jongsoon Kim ${ }^{1}$, Saesook $\mathrm{Oh}^{2, *}$ and Boonhong Yeon ${ }^{3, *}$ \\ 1 Division of Sports Science, Leisure Welfare Culture Institute, Kyonggi University, Suwon-si 16200, Korea; \\ sdivertido@hanmail.net \\ 2 Division of Sports Science, Major in Sport \& Leisure Industry, Kyonggi University, Suwon-si 16200, Korea \\ 3 Department of Sports Studies, Soongsil University, Seoul 01024, Korea \\ * Correspondence: penn_sso@kgu.ac.kr (S.O.); pink6066@naver.com (B.Y.)
}

check for

updates

Citation: Kim, J.; Oh, S.; Yeon, B. A Study on Types of Leisure Index Based on National Leisure Activities Survey 2019 in Korea. Sustainability 2021, 13, 3619. https://doi.org/ $10.3390 /$ su13073619

Academic Editors: Damián Iglesias Gallego, Juan Pedro Fuentes García and José Alberto Frade Martins Parraca

Received: 17 February 2021

Accepted: 22 March 2021

Published: 24 March 2021

Publisher's Note: MDPI stays neutral with regard to jurisdictional claims in published maps and institutional affiliations.

Copyright: (c) 2021 by the authors. Licensee MDPI, Basel, Switzerland. This article is an open access article distributed under the terms and conditions of the Creative Commons Attribution (CC BY) license (https:// creativecommons.org/licenses/by/ $4.0 /)$.

\begin{abstract}
This study investigated differences in main purposes of leisure activities, leisure constraints, and the quality of life among segmented clusters based on leisure condition index, leisure resource index, and leisure attitude index utilizing Korean Better Leisure Index (K-BLI). Characteristics of each cluster were aggregated for profiling using data from the `National Leisure Activity Survey 2019」 in Korea. Results of this study provide room for debate and response regarding leisure experience and sustainability of recreation service in local community based on characteristics of each cluster. This study semanticized adults living in Gyeonggi-do having the highest population density in Korea by conducting K-means clustering. This study segmented subjects into three clusters. Characteristics of each cluster were determined and $t$-test was conducted to determine associations among the main purpose of leisure activities, leisure constraints, and quality of life. As a result, adults living in Gyeonggi-do were divided into "dissatisfaction with leisure resource", "dissatisfaction with the quality of life", and "sensitive to the leisure constraints" clusters. Their desire for improvement for quality of life and leisure activity were definitely clear. This means that results of this study through segmentation based on leisure index are meaningful as baseline data to suggest an actual policy plan.
\end{abstract}

Keywords: leisure index; quality of life; Gyeonggi-do

\section{Introduction}

Recent advances in science and technology have led to a phenomenon of reducing working hours and increasing leisure time in our society. How mankind will spend its free time is one of the greatest tasks of the century and leisure has become an important goal and part of life for living in modern society [1]. Many scholars have proven that the most influential thing in raising individual happiness index is to spend leisure time of their own choice [2,3]. However, according to the World Happiness Report of a U.N., Koreans' happiness level has remained at the bottom 61st place in the past few years, lower than that of OECD (Organisation for Economic Co-operation and Development) countries. This means that South Korea is literally at the back of the pack now [4]. Therefore, we should pay more attention to leisure for the sake of the happy life of Koreans. Results of National Leisure Activities Survey of Korea 2019 have shown that Koreans' leisure time in weekdays, weekends, and holidays is steadily increasing over the past three years [5]. As leisure time increases, how does leisure activity differ depending on individual leisure conditions? In general, an increase in leisure time and opportunities will have a positive impact on individual leisure satisfaction and quality of life. However, based on previous researches, that is not always true [6,7]. Lee and Hwang [3], for example, have reported that a certain amount of increased leisure time has negative influences on every sub-factor such as sociability, self-control, receptivity to change, and so on. In other words, the increasing amount of leisure time cannot be directly related to the qualitative satisfaction of individual leisure activities. It is important to be careful not to confuse quantity with quality. Thus, 
measuring the multi-phasic leisure index that influences the satisfaction of leisure activities or quality of life is required other than fragmentary conditions such as a total amount of leisure time.

Leisure index consists of items which that can objectively measure an individual's leisure environment. It might be a useful indicator to find priorities and effectiveness of policies that will improve the level of happiness [8]. It is difficult to segment social, economic, and environmental requirement of members in our society and give proper service. However, the sustainability of leisure that holds the maximum level of leisure experience and recreation service has to be made [9]. As a way to overcome problems in Korea with a relatively low level of happiness, leisure index and developing typology should be analyzed.

Personal condition index, leisure condition index, and leisure attitude are examples of measurement items for the analysis of leisure index. First, the personal condition index is based on the sufficiency of time and expenditure. Specifically, a study on leisure time sufficiency and freedom among leisure indexes has reported that self-distributed time and perceived leisure attitude have an effect on the quality of leisure experience and leisure satisfaction in work-leisure-family balance [10]. How individuals enjoy their own leisure time is also important because the degree of freedom is one of the most crucial factors in an individual's leisure experience in work-life or work-family balance. Among leisure constraints that affect leisure satisfaction, leisure expenditure is considered as an important factor as leisure time. Evidence suggests that economic problem such as leisure expenditure can directly affect leisure satisfaction. It is one of the reasons for quitting participation in leisure [11-13]. There were also studies on the relationship between leisure constraints and leisure expenditure. Early studies that identified the causes of leisure constraints and leisure expenditure reported that leisure participation, leisure constraints and leisure expenditure had an interactive effect [14]. For example, Godbey, Crawford and Shen [15] reported that the burden of leisure expenditure was correlated with leisure constraints. It can be inferred that the degree of personal leisure satisfaction is closely related to the amount of money spent on leisure.

Second, the leisure condition index includes satisfaction with public/private facilities and programs. In a previous research regarding public/private facilities and programs, Heo [16] has reported that accessibility of facilities and diversity of programs have a positive effect on leisure participation and leisure satisfaction. Hong and Kim [17] have also shown that facilities and program infrastructure in rural areas are generally less sufficient compared to those in urban areas in the case of leisure welfare facilities for the elderly and that environmental factors can act as leisure constraints. Accessibility is one of the important leisure motivation for leisure participants [18], physical access to leisure space is a major factor in their leisure life. Specially, according to Nam [19] research regarding the assessment of leisure facility and accessibility, spatial accessibility such as leisure facillities in residence increased the opportunity of leisure participation for the participants. It means that accessibility and convenience of facilities and programs as structural variables that provide easy access to leisure are also crucial factors that can affect leisure satisfaction.

Lastly, leisure attitude index, a measure of leisure perception, is an important social and psychological variable to improve leisure satisfaction [20]. Manfredo and Yuan [21] have reported that life satisfaction and positive emotion through leisure activities come from an individual's leisure attitude. Additionally, Peterson and Seligman [22] have suggested that leisure attitude, a process of motivation that can lead to an active leisure participation, is an important factor that can bring a qualitatively high level of leisure satisfaction.

Previous researchers have informed that analysis on leisure index as an interior and exterior environment to enjoy leisure reflects leisure experience and sociocultural characteristics. The cause of leisure constraints and dissatisfaction even though individuals have already participated in leisure activities might be activated by not only a personal problem, but also external factors $[15,23,24]$. 
Applying the leisure index is helpful to segment personal leisure condition. Furthermore, it can be used as base data to provide leisure service that local societies require. The administrative district of South Korea consists of one metropolitan government, six metropolitan cities, eight provinces, one special self-governing province, and one special self-governing city. A total of 17 administrative districts are classified as metropolitan and provincial governments. Gyeonggi-do, selected as a research area for the study, is located in the northwestern part of South Korea. It is surrounding Seoul Metropolitan Government and Incheon Metropolitan City and is about 1.5 times the size of Seoul. Also, Gyeonggi-do is the only one among eight provinces in South Korea with the highest population ratio of more than 10 million, with a total of 31 administrative districts. The characteristic of Gyeonggi-do is that geographical conditions with natural environments as well as urban environments where people can enjoy leisure as a complex area of urban and rural areas are created.

Therefore, it is necessary to identify individual leisure index for Gyeonggi-do with these characteristics, and to identify the deviation of leisure experience accordingly, and to provide differentiated leisure services. Cluster analysis is used for segmentation and positioning of leisure participants [25-27]. K-means clustering is one of the most popular methods to select indexes and divides the clusters based on common characteristics and similarity. It serves as a basis for segmenting specific areas, ages, occupational groups, etc. and providing appropriate leisure services.

Thus, the purpose of the study was to segment clusters according to leisure index focusing on Gyeonggi-do and find out differences in the main purpose of leisure, leisure constraints, and quality of life using data from National Leisure Activities Survey of Korea 2019. Clusters were segmented according to leisure condition index, leisure resource index, and leisure attitude index utilized to measure K-BLI [8]. According to these clusters, this study analyzed differences among main purposes of leisure, leisure constraints, and quality of life. Characteristics of each cluster were profiled at the same time. Results of this study provide a room for debate and response regarding leisure experience and sustainability of leisure service in local community based on characteristics of each cluster.

\section{Methodology}

\subsection{Data Collection}

Data from this study originated from the National Leisure Activities Survey of Korea 2019. The survey included 10,000 people aged over 15 years nationwide. Among them, this study used 1263 adults aged 20 or older living in Gyeonggi-do for the analysis. Table 1 summarizes demographic characteristics of respondents.

The proportion of females $(n=643,50.9 \%)$ was slightly higher than that of males. This study included 266 people in their 40s, 251 people in their 50s, 236 people in their 30s, 196 people in their 20s, 165 people in their 60s, and 149 aged 70 years or more. In terms of educational level, the majority of subjects graduated from high school (40.4\%) and college $(45.2 \%)$.

Regarding the level of monthly income, 3-4 million KRW had the highest proportion ( $n=258,20.4 \%)$, followed by $4-5$ million KRW $(n=239,18.9 \%)$ and 5-6 million KRW $(n=229,18.1 \%)$. More than three-quarters of respondents (81\%) lived in cities (all cities except for metropolitan). 
Table 1. Socio-demographic Characteristics of Respondents.

\begin{tabular}{|c|c|c|}
\hline Variables. & $n$ & $\%$ \\
\hline \multicolumn{3}{|l|}{ Gender. } \\
\hline Male & 620 & 49.1 \\
\hline Female & 643 & 50.9 \\
\hline \multicolumn{3}{|l|}{ Age } \\
\hline $20 \mathrm{~s}$ & 196 & 15.5 \\
\hline $30 \mathrm{~s}$ & 236 & 18.7 \\
\hline $40 \mathrm{~s}$ & 266 & 21.1 \\
\hline $50 \mathrm{~s}$ & 251 & 19.9 \\
\hline $60 \mathrm{~s}$ & 165 & 13.1 \\
\hline Over 70s & 149 & 11.8 \\
\hline \multicolumn{3}{|l|}{ Education } \\
\hline Less than grades 7 & 80 & 6.3 \\
\hline Completed middle high school & 102 & 8.1 \\
\hline Completed high school & 510 & 40.4 \\
\hline Completed College & 571 & 45.2 \\
\hline \multicolumn{3}{|l|}{ Monthly Income } \\
\hline Less than $1 \mathrm{M}$ KRW & 91 & 7.2 \\
\hline 1 2 M KRW & 112 & 8.9 \\
\hline 2 3 M KRW & 147 & 11.6 \\
\hline 3 4 M KRW & 258 & 20.4 \\
\hline 4 5 M KRW & 239 & 18.9 \\
\hline 5 6 M KRW & 229 & 18.1 \\
\hline Over 6 M KRW & 187 & 14.8 \\
\hline \multicolumn{3}{|l|}{ Region } \\
\hline Urban & 1036 & 82.0 \\
\hline Rural & 227 & 18.0 \\
\hline Total & 1263 & 100 \\
\hline
\end{tabular}

Note: 1000 KRW (Korean Won) = 1 USD, M = million.

\subsection{Measure}

To find socio-demographic characteristics, gender, age, educational level, income level, and region where subjects were living were determined. K-BLI is divided into leisure condition index, leisure resource index, and leisure attitude index [8]. Leisure condition index consists of leisure time sufficiency (e.g., Do you think you have enough leisure time over the past year?), leisure time freedom (e.g., Do you think you are freely using your leisure time without interference from work, family, etc.?), and leisure expenditure sufficiency (e.g., What do you think of the leisure expenditure you spent over the past year?). Leisure resource index consists of public leisure facilities and program sufficiency (e.g., Do you think that you have enough public facilities and programs for leisure?) and satisfaction in private leisure-related place industry (e.g., What do you think about leisurerelated space industry?). Leisure attitude index consists of the perception of leisure (e.g., Do you think leisure is an essential requirement of life?) and perception of leisure effect (e.g., Do you think leisure has a positive effect on life?). Additionally, questions about the main purpose of leisure (e.g., What is your main purpose of having leisure?), leisure constraints (i.e., lack of time, economic burden, fine dust, intense heat and cold weather, family health, etc.), and quality of life (i.e., perceived health status, work-life balance, leisure satisfaction, happiness) were used. A nominal scale was used for questions about socio-demographic and the main purpose of leisure. In case of questions about leisure constraints and quality of life, a 7-point scale ( $1=$ not at all, $7=$ a lot) were used for measurement. A 10-point scale $(1=$ not at all, $10=\mathrm{a}$ lot $)$ was used for measuring questions about happiness. 


\subsection{Data Collection and Analysis}

For data analysis to find socio-demographic characteristics, descriptive analysis was conducted. To identify the typology of subjects according to a better leisure index, K-means clustering was conducted. K-means clustering is one of the most popular methods that can calculate the distance between each object to make them as one typology [28]. Unlike hierarchical clustering, the number of clusters is determined by researchers. To find out the association of socio-demographic characteristics and the main purpose of leisure, a Chi-square test was performed. Additionally, the association of leisure attitude and quality of life was analyzed by one-way analysis of variance (ANOVA) using SPSS 25.0. The significance level was set at $\alpha=0.05$.

\section{Results}

\subsection{Cluster Analysis}

This study conducted k-means clustering analysis to classify clusters of adults aged 20 years and over who were living in Gyeonggi-do based on leisure index. Three clusters were determined to explain the distribution of clusters and characteristics of each cluster (see Tables 2 and 3).

Table 2. Number of Clusters by Leisure Index.

\begin{tabular}{cccc}
\hline & $\mathbf{5}$ & $\mathbf{4}$ & $\mathbf{3}$ \\
\hline Cluster 1 & 145 & 316 & 444 \\
Cluster 2 & 335 & 261 & 413 \\
Cluster 3 & 291 & 307 & 406 \\
Cluster 4 & 213 & 397 & \\
Cluster 5 & 279 & & 1263 \\
$n$ & 1263 & 1263 & \\
\hline
\end{tabular}

Table 3. Characteristics of Clusters by Leisure Index.

\begin{tabular}{|c|c|c|c|c|}
\hline Variables. & Cluster 1 & Cluster 2 & Cluster 3 & $\mathbf{F}$ \\
\hline Leisure Condition & & & & \\
\hline Leisure time sufficiency & $4.91^{b}$ & $3.09^{c}$ & $5.30^{\mathrm{a}}$ & $586.30 * * *$ \\
\hline Leisure time freedom & $5.03^{b}$ & $3.20^{c}$ & $5.29^{a}$ & $549.39 * * *$ \\
\hline $\begin{array}{c}\text { Leisure expenditure sufficiency } \\
\text { Leisure Resource }\end{array}$ & $4.31^{\mathrm{b}}$ & $4.02^{c}$ & $5.11^{\mathrm{a}}$ & $107.53^{* * *}$ \\
\hline Public leisure facilities sufficiency & $3.43^{c}$ & $4.16^{\mathrm{b}}$ & $5.57^{\mathrm{a}}$ & $597.97^{* * *}$ \\
\hline Public leisure programs sufficiency & $3.41^{\mathrm{c}}$ & $4.02^{b}$ & $5.37^{\mathrm{a}}$ & $546.00 * * *$ \\
\hline $\begin{array}{c}\text { Satisfaction in private leisure-related } \\
\text { place industries } \\
\text { Leisure Attitude }\end{array}$ & $4.39^{c}$ & $4.77^{b}$ & $5.45^{\mathrm{a}}$ & $149.82 * * *$ \\
\hline Perception of leisure & $5.24^{b}$ & $5.51^{\mathrm{a}}$ & $5.63^{\mathrm{a}}$ & $17.67^{* * *}$ \\
\hline Perception of leisure effect & $5.34^{\mathrm{b}}$ & $5.63^{\mathrm{a}}$ & $5.68^{a}$ & $17.72^{* * *}$ \\
\hline
\end{tabular}

The first cluster included 444 people. They showed the lowest level of leisure resource index and leisure attitude index. In other words, their satisfaction in public leisure facilities and programs' sufficiency and their satisfaction in private leisure-related place industries were relatively low. Their perceptions of leisure and leisure effect were also relatively lower than other clusters.

The second cluster included 413 people. Their level of the leisure condition index was the lowest. They had the lowest degree of leisure time sufficiency and leisure time freedom. Their degree of leisure expenditure sufficiency was also relatively low. However, their overall level of leisure attitude index that 'leisure is essential in life with a positive effect' was high. 
The third cluster included 406 people. All sub-factors of leisure condition index were high for this cluster. They had enough time for leisure. They were free enough to enjoy leisure. They also had enough budget for leisure. Their levels of leisure resource index, satisfaction in public leisure facilities and programs' sufficiency, and satisfaction in private leisure-related place industry were high. They also had a high level of leisure attitude.

\subsection{Typology of Clusters}

To find statistical associations among socio-demographic characteristics, the main purpose of leisure, leisure constraints, and quality of life, $t$-test was conducted. Using difference of each variable, this study determined comprehensive characteristics of each cluster. $\chi^{2}$ test was carried out to analyze socio-demographic characteristics of each cluster. Results are shown in Table 4 . As a result, the first cluster had a population of those over 50s (88 subjects, $19.8 \%$ ) and those over 70 s (77 subjects, $17.3 \%$ ) more than other clusters. This cluster also had higher ratios of those with monthly income of $3 \sim 4$ million KRW (78 subjects, $17.6 \%$ ) and those with a high school diploma (189 subjects, $42.6 \%$ ) compared to other clusters. Plus, this cluster had much higher percentage of residents living in suburban area compared to other clusters. Regarding the second cluster, many subjects were in their 30 s or 40 s ( 227 subjects, $34.9 \%)$ and the majority ( $81 \%$ ) of them had monthly income of more than 3 million KRW. The percentage of those who completed college was $53.3 \%$ (220 subjects). The majority $(86.4 \%)$ of them were living in small and medium sized cities. The third cluster had a high percentage of subjects in their 40s-50s (155 subjects, $38.2 \%)$. A total of 69 subjects earn more than 6 million KRW per a month. The percentage of those who completed college was high (193 subjects, $47.5 \%)$. The majority (86.5\%, 351 subjects) of them were living in small and medium sized cities.

Table 4. Difference in Socio-demographic Characteristics by Clusters of Leisure Index.

\begin{tabular}{|c|c|c|c|c|c|}
\hline & $\begin{array}{l}\text { Cluster1 } \\
(n=444)\end{array}$ & $\begin{array}{l}\text { Cluster2 } \\
(n=413)\end{array}$ & $\begin{array}{l}\text { Cluster3 } \\
(n=406)\end{array}$ & Total & $\mathbf{F}$ \\
\hline $\begin{array}{c}\text { Age } \\
20 \mathrm{~s} \\
30 \mathrm{~s} \\
40 \mathrm{~s} \\
50 \mathrm{~s} \\
60 \mathrm{~s} \\
\text { Over } 70 \mathrm{~s}\end{array}$ & $\begin{array}{l}75(16.9 \%) \\
70(15.8 \%) \\
69(15.5 \%) \\
88(19.8 \%) \\
65(14.6 \%) \\
77(17.3 \%)\end{array}$ & $\begin{array}{c}53(12.8 \%) \\
105(25.4 \%) \\
122(29.5 \%) \\
83(20.1 \%) \\
41(9.9 \%) \\
9(2.2 \%)\end{array}$ & $\begin{array}{l}68(16.7 \%) \\
61(15.0 \%) \\
75(18.5 \%) \\
80(19.7 \%) \\
59(14.5 \%) \\
63(15.5 \%)\end{array}$ & $\begin{array}{l}196(15.5 \%) \\
236(18.7 \%) \\
266(21.1 \%) \\
251(19.9 \%) \\
165(13.1 \%) \\
149(11.8 \%)\end{array}$ & $\begin{array}{c}\chi^{2}=93.002^{* * * *} \\
\mathrm{df}=10\end{array}$ \\
\hline $\begin{array}{c}\text { Income level } \\
\text { less than } 1 \mathrm{M} \\
1-2 \mathrm{M} \\
2-3 \mathrm{M} \\
3-4 \mathrm{M} \\
4-5 \mathrm{M} \\
5-6 \mathrm{M} \\
\text { Over } 6 \mathrm{M}\end{array}$ & $\begin{array}{l}55(12.4 \%) \\
56(12.6 \%) \\
57(12.8 \%) \\
78(17.6 \%) \\
70(15.8 \%) \\
69(15.5 \%) \\
59(13.3 \%)\end{array}$ & $\begin{array}{c}10(2.4 \%) \\
23(5.6 \%) \\
45(10.9 \%) \\
99(24.0 \%) \\
85(20.6 \%) \\
92(22.3 \%) \\
59(14.3 \%)\end{array}$ & $\begin{array}{c}26(6.4 \%) \\
33(8.1 \%) \\
45(11.1 \%) \\
81(20.0 \%) \\
84(20.7 \%) \\
68(16.7 \%) \\
69(17.0 \%)\end{array}$ & $\begin{array}{c}91(7.2 \%) \\
112(8.9 \%) \\
147(11.6 \%) \\
258(20.4 \%) \\
239(18.9 \%) \\
229(18.1 \%) \\
187(14.8 \%)\end{array}$ & $\begin{array}{c}\chi^{2}=59.256^{* * *} \\
\mathrm{df}=12\end{array}$ \\
\hline $\begin{array}{c}\text { Educational level } \\
\text { Less than grades } 7 \\
\text { Completed Middle school } \\
\text { Completed High school } \\
\text { Completed College }\end{array}$ & $\begin{array}{l}47(10.6 \%) \\
50(11.3 \%) \\
189(42.6 \%) \\
158(35.6 \%)\end{array}$ & $\begin{array}{l}11(2.7 \%) \\
21(5.1 \%) \\
161(39.0 \%) \\
220(53.3 \%)\end{array}$ & $\begin{array}{l}22(5.4 \%) \\
31(7.6 \%) \\
160(39.4 \%) \\
193(47.5 \%)\end{array}$ & $\begin{array}{c}80(6.3 \%) \\
102(8.1 \%) \\
510(40.4 \%) \\
571(45.2 \%)\end{array}$ & $\begin{array}{c}\chi^{2}=48.580 * * * \\
\mathrm{df}=6\end{array}$ \\
\hline $\begin{array}{l}\text { Region } \\
\text { cities } \\
\text { counties }\end{array}$ & $\begin{array}{l}328(73.9 \%) \\
116(26.1 \%)\end{array}$ & $\begin{array}{c}357(86.4 \%) \\
56(13.6 \%)\end{array}$ & $\begin{array}{c}351(86.5 \%) \\
55(13.5 \%)\end{array}$ & $\begin{array}{c}1036(82.0 \%) \\
227(18.0 \%)\end{array}$ & $\begin{array}{c}\chi^{2}=30.872 \\
\mathrm{df}=2\end{array}$ \\
\hline
\end{tabular}


To find difference in the main purpose of leisure per each cluster, $\chi^{2}$ test was conducted (see Table 5). As a result, it was found that every cluster enjoyed leisure for personal happiness and relaxation. Besides such purposes, $11.9 \%$ of respondents (53 subjects) reported that they enjoyed leisure for health. The second and third clusters reported that they enjoyed leisure to recover from stress.

Table 5. Difference in the Main Purpose of Leisure by Clusters.

\begin{tabular}{|c|c|c|c|c|c|}
\hline Variables & $\begin{array}{l}\text { Cluster1 } \\
(n=444)\end{array}$ & $\begin{array}{l}\text { Cluster2 } \\
(n=413)\end{array}$ & $\begin{array}{l}\text { Cluster3 } \\
(n=406)\end{array}$ & Total & F \\
\hline Perceived Health & $53(11.9 \%)$ & $20(4.8 \%)$ & $38(9.4 \%)$ & $111(8.8 \%)$ & \\
\hline Personal enjoyment & $151(34.0 \%)$ & $116(28.1 \%)$ & $145(35.7 \%)$ & $412(32.6 \%)$ & \\
\hline Relaxation & $86(19.4 \%)$ & $111(26.9 \%)$ & $83(20.4 \%)$ & $280(22.2 \%)$ & \\
\hline Interpersonal relationship & $29(6.5 \%)$ & $24(5.8 \%)$ & $17(4.2 \%)$ & $70(5.5 \%)$ & \\
\hline Stress relief & $45(10.1 \%)$ & $57(13.8 \%)$ & $59(14.5 \%)$ & $161(12.7 \%)$ & $\chi^{2}=51.993^{* * *}$ \\
\hline Self-improvement & $9(2.0 \%)$ & $6(1.5 \%)$ & $7(1.7 \%)$ & $22(1.7 \%)$ & $\mathrm{df}=18$ \\
\hline Self-satisfaction & $31(7.0 \%)$ & $26(6.3 \%)$ & $25(6.2 \%)$ & $82(6.5 \%)$ & \\
\hline Killing time & $26(5.9 \%)$ & $17(4.1 \%)$ & $22(5.4 \%)$ & $65(5.1 \%)$ & \\
\hline With family & $14(3.2 \%)$ & $35(8.5 \%)$ & $10(2.5 \%)$ & $59(4.7 \%)$ & \\
\hline others & $0(0.0 \%)$ & $1(0.2 \%)$ & $0(0.0 \%)$ & $1(0.1 \%)$ & \\
\hline
\end{tabular}

ANOVA was conducted to find difference in leisure constraints among clusters. Results are shown in Table 6 . The first cluster perceived less leisure constraints than the other two clusters. Especially, leisure constraints due to a lack of time and hot/cold weather were the lowest compared to other clusters.

Table 6. Difference in Leisure Constraints by Clusters.

\begin{tabular}{ccccc}
\hline Variables & $\begin{array}{c}\text { Cluster1 } \\
(\boldsymbol{n}=\mathbf{4 4 4 )}\end{array}$ & $\begin{array}{c}\text { Cluster2 } \\
(\boldsymbol{n}=\mathbf{4 1 3})\end{array}$ & $\begin{array}{c}\text { Cluster3 } \\
(\boldsymbol{n}=\mathbf{4 0 6})\end{array}$ & F \\
\hline Lack of time & $4.64^{\mathrm{c}}$ & $5.68^{\mathrm{a}}$ & $5.13^{\mathrm{b}}$ & $57.60^{* * *}$ \\
Economic burden & $5.40^{\mathrm{b}}$ & $5.75^{\mathrm{a}}$ & $5^{\mathrm{a}}$ & $10.26^{* * *}$ \\
Fine dust & $4.82^{\mathrm{b}}$ & $5.24^{\mathrm{a}}$ & $5.35^{\mathrm{a}}$ & $19.83^{* * *}$ \\
Hot and cold weather & $4.80^{\mathrm{c}}$ & $5.14^{\mathrm{b}}$ & $5.33^{\mathrm{a}}$ & $18.63^{* * *}$ \\
Family health & $4.59^{\mathrm{b}}$ & $4.78^{\mathrm{b}}$ & $5.03^{\mathrm{a}}$ & $7.52^{* * *}$ \\
\hline F** & & & &
\end{tabular}

***, $p<0.001$. Post-Hoc Test a $>\mathrm{b}>\mathrm{c}$.

The second cluster perceived leisure constraints due to the lack of time more than other clusters. They were also sensitive to economic burden and fine dust. The third cluster perceived everything as their leisure constraints except the lack of time.

ANOVA was conducted to analyze the difference in quality of life among clusters. Results are shown in Table 7. As a result, the first cluster showed lower levels of perceived health and happiness. The second cluster perceived that their health status was good. However, they perceived the lowest level of leisure satisfaction and work-life balance. Their levels of happiness were relatively low compared to other clusters. The third cluster showed higher levels of perceived health, work-life balance, leisure satisfaction, and happiness. Their quality of life was higher than other clusters. 
Table 7. Difference in Quality of Life by Clusters.

\begin{tabular}{ccccc}
\hline Variables. & $\begin{array}{c}\text { Cluster1 } \\
(\boldsymbol{n}=\mathbf{4 4 4 )}\end{array}$ & $\begin{array}{c}\text { Cluster2 } \\
(\boldsymbol{n}=\mathbf{4 1 3 )}\end{array}$ & $\begin{array}{c}\text { Cluster3 } \\
(\boldsymbol{n}=\mathbf{4 0 6})\end{array}$ & F \\
\hline Subjective health status & $4.90^{\mathrm{b}}$ & $5.09^{\mathrm{a}}$ & $5.22^{\mathrm{a}}$ & $7.72^{* * *}$ \\
Work-life balance & $4.04^{\mathrm{b}}$ & $3.38^{\mathrm{c}}$ & $4.50^{\mathrm{a}}$ & $91.46^{* * *}$ \\
Leisure life satisfaction & $4.52^{\mathrm{b}}$ & $4.00^{\mathrm{c}}$ & $5.22^{\mathrm{a}}$ & $133.54^{* * *}$ \\
Happiness & $6.76^{\mathrm{b}}$ & $6.67^{\mathrm{b}}$ & $7.34^{\mathrm{a}}$ & $26.30^{* * *}$ \\
$\overline{* * *}, p<0.001$. Post-Hoc Test a $>\mathrm{b}>\mathrm{c}$. & & &
\end{tabular}

Associations among socio-demographic characteristics, main purpose of leisure, leisure constraints, and quality of life were analyzed. Results are shown in Table 8. The first cluster could be called "dissatisfaction with leisure resource". The second cluster could be called "unbalance of attitude and quality of life". The third cluster could be called "sensitivity to leisure constraints".

Table 8. Characteristics of Each Cluster.

\begin{tabular}{|c|c|}
\hline \multicolumn{2}{|r|}{ Characteristics. } \\
\hline $\begin{array}{l}\text { Dissatisfaction to } \\
\text { leisure resource }\end{array}$ & $\begin{array}{l}\text { - } \quad \text { the lowest level of satisfaction with public leisure facilities, } \\
\text { - } \quad \text { programs, and private leisure-related place industries } \\
\text { - } \quad \text { the highest proportion of people over } 70 \text { years among clusters } \\
\text { - } \quad \text { many people living in rural } \\
\text { - } \quad \text { leisure for happiness, relaxation, and health } \\
\text { - } \quad \text { the lowest level of lack of time }\end{array}$ \\
\hline $\begin{array}{l}\text { Unbalance of attitude } \\
\text { and quality of life }\end{array}$ & $\begin{array}{ll}\text { - } & \text { very low degree of leisure time freedom, but high leisure attitude } \\
\text { - } & \text { the highest proportion of people in their } 30 \text { s to } 40 \text { s among clusters } \\
\text { - } & \text { high level of education and monthly income } \\
\text { - } & \text { leisure for happiness, relaxation, and stress relief } \\
\text { - } & \text { high level of lack of time, economic burden, and fine dust } \\
\text { - } & \text { lower level of work-life and quality of life }\end{array}$ \\
\hline $\begin{array}{l}\text { Sensitivity to leisure } \\
\text { constraints }\end{array}$ & 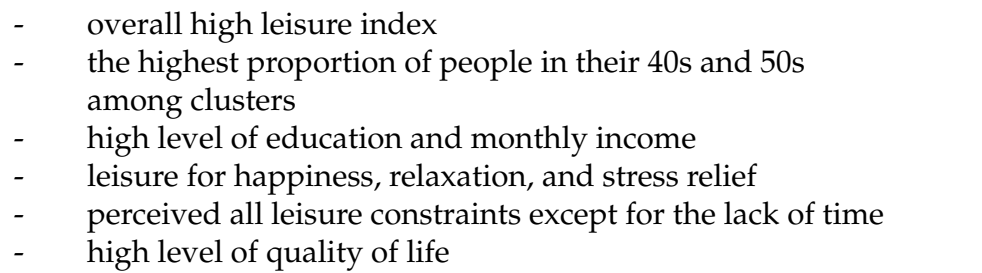 \\
\hline
\end{tabular}

Taking a close look, the first cluster did not have enough public facilities or programs. Those in the first cluster tended to have a negative perception about leisure or the effect of a leisure activity. This cluster had higher percentage of those aged over $70 \mathrm{~s}$ and residents in suburban area compared to other clusters. Their purpose of leisure activity was for their health. Their constraints about lack of time were the lowest. That was the reason why this cluster was called "dissatisfaction with leisure resource".

The second cluster had many highly educated and high-income individuals who did not have enough time for leisure. Their constraints were lack of time, economic reason, and fine dust. They tended to perceive that their quality of life and work-life balance were poor. However, their levels of perception for 'leisure is essential with positive effect on life' were high. Therefore, this study named this cluster "unbalance of attitude and quality of life" because they had positive leisure attitude but poor quality of life.

Lastly, the third cluster had enough time and budget for leisure. They also had access to leisure facilities and programs with satisfaction about the leisure industry. They had a high degree of perceived leisure and its positive effect. This cluster had a high ratio of highly educated subjects in their 40s and 50s with a high level of income. Their perceived 
degree of happiness was also high. However, they perceived constraints to leisure were economic reason, fine dust, hot and cold weather, and family's health. Therefore, the cluster was named as "sensitivity to leisure constraints" because they had leisure constraints even although they had a high quality of life.

After all analyses, people age over 20 years who were living in Gyeonggi-do were classified into three clusters of "dissatisfaction with leisure resource", "dissatisfaction with quality of life" and "sensitivity to leisure constraints". It featured definite demands of better quality of life and improvement. Results of this study based on the National Leisure Activities Survey of Korea 2019 are meaningful as baseline data to suggest an actual policy plan.

\section{Discussion}

Recently, individualization on leisure activity is a marked phenomenon. It is prevalent that the purpose of leisure is to pursue a better life and to manage a happy life [8]. Thus, this study segmented the individualization of leisure index per each cluster and analyzed the difference among their purposes of leisure, leisure constraints, and quality of life. Furthermore, this study profiled characteristics of each cluster to provide baseline data to suggest differential leisure services for local communities.

Data used in this study originated from the National Leisure Activities Survey of Korea 2019. Clusters were segmented according to leisure condition index, leisure resource index, and leisure attitude index utilized to measure K-BLI. The typology was processed focusing on adults living in Gyeonggi-do having the highest population density in Korea by conducting K-means clustering. The typology was finalized as three clusters with even distribution and characteristics. A $t$-test was then conducted to find associations among main purposes of leisure, leisure constraints, and quality of life for each cluster. Results of this study are discussed as follows.

\subsection{Typology of Leisure Index}

As a result of clustering analysis, it was found out that the first cluster showed the lowest level of leisure resource index and leisure attitude index. The second cluster had the lowest leisure condition index. The third cluster, sensitivity to leisure constraints, had higher level of leisure condition index, leisure resource index, and leisure attitude index. When ANOVA was performed to determine differences in socio-demographic characteristics, the main purpose of leisure, leisure constraints, and quality of life per each cluster, it was found that each cluster had its own characteristics. It was meaningful as this study showed the segmentation of leisure type according to characteristics of each cluster.

To be concrete, in an instance of the first cluster, they tended to dissatisfy with leisure resource. They were more likely to live in suburban areas. In this study, leisure resource means a level of satisfaction with public leisure facilities or programs and private leisurerelated place industries. In other words, compared to small and medium-sized cities with enough infrastructure for leisure activities, people living in suburban communities have less leisure resource which brings dissatisfaction. Bell and Menguc [29] have reported that service satisfaction with local leisure facilities has a positive impact on future leisure behavior intention as it affects community attachment and dependency. Additionally, Kim and Ko [30] have analyzed the situation of sports facilities in urban and suburban areas and found that there are more opportunities in the urban area. The action plan for sport facilities by the Ministry of Culture and Sports of Korea [31] with accessibility to public sports facilities as the reference point of supply supports quantitative expansion.

However, in small towns, there is a shorter supply of sports facilities than metropolis. In modern society, the residence is not just a living place. The residential environment with various and comfortable leisure facilities becomes an important element for life. Facility expansion connects directly to an individual's leisure attitude and leisure satisfaction. Therefore, the expansion of leisure facilities and programs for people in their 70s or older is needed for suburban areas as shown in this study. 
Regarding the first cluster with the highest proportion of the population in their 70s or older, leisure constraints such as lack of time for leisure were lower than those of the other clusters. It might be due to expanded leisure time as they retired from work. Thus, they had a relatively low time pressure. According to Consumer Expenditure Survey by Weagley and Huh [32], the actual spending for leisure activities after retirement is a crucial variable for individual's family budget expenditure. With an integrated point of view, environmental elements had a negative impact on leisure resource index and leisure attitude index. Thus, to have more leisure facilities in suburban area and infrastructure for varied age, administrative and financial supports for each local community are necessary.

Secondly, results of the analysis for associations among socio-demographic characteristics, purpose of leisure, leisure constraints, and quality of life of the second cluster showed the lowest leisure condition index. Results revealed that a relatively high percentage of subjects in the second cluster perceived leisure constraints due to lack of time. Given the high proportion of those in their 30s and 40s in the second cluster compared to those in other clusters, it was inferred that they had the lack of time as a constraint due to many social activities such as work. Lee, Zvonkovic and Crawford [33] have reported that the cause of lack of time is related to the double role of married workers and the flexibility of social organization. Additionally, Lyu and Oh [34] have found that people are unable to participate in leisure activities as much as they want due to various constraints such as lack of time.

The positive perception to leisure can be understood in the same context of the result of a previous study concluding that leisure is a reason of the existence and identity of an individual. One background is the current situation of a rising interest in work-life balance (WLB). Since this study deduced that the main purpose of leisure was to achieve relaxation and provide a solution for stress, it is obvious that an individual tends to feel happy through quantitative and qualitative experience of leisure. Also, since work-life balance is one of the most considerable issues not only for an individual, but also for society, proper distribution of leisure time is required for leisure attitude and qualitative balance of life [35].

Thirdly, the third cluster had the highest level of quality of life among all clusters. Their health, work-life balance, leisure satisfaction, and happiness were higher. On the other hand, they tended to have a lot of leisure constraints such as economic burden, fine dust, hot and cold weather, and family health. This result was related to the situation that a higher proportion of subjects in this study had high income and educational level than other clusters. According to Godbey, Crawford and Shen [15], factors of leisure constraints have close connections with one another depending on personal characteristics. Lee [13] has also reported that the economic problem had a direct influence on leisure constraints. In the research of Park and Park [36], it was reported that the lower a physical and economic burden is, the higher an individual's leisure and life satisfaction are. Especially, the third cluster tended to feel environmental constraints such as fine dust, hot and cold weather and family member's health. The result is in the same context of the study of Lopez-Mosquera and Sanchez [37]. They have reported the importance of environmental condition or reliving stress and reducing tiredness.

\subsection{Limitations}

Based on the result of this study, limitations and suggestion for future researches can be provided as follows: First, the data used in this study were limited to using various variables as the national survey panel data. Therefore, further studies will need to be conducted including various variables such as leisure attitude, leisure activity type and leisure satisfaction. Second, the province, Gyeonggi-do, was selected and studied as a specific area, so there is a limit to explaining the leisure index of all regions in South Korea. Thus, future researches need to expand the coverage to nationwide. Lastly, since the study extract the characteristics of each cluster through profiling using K-means clustering, so in 
future researches, it is necessary to analyze the associations among variables with more multi-phasic methodology.

\subsection{Implications}

This study divided the clusters according to the leisure index and analyzed the difference of socio-demographic characteristics, leisure constraints and quality of life. Each cluster will help professionals in specialized areas such as sports, health, and public leisure facilities understand their targets better. The cluster called "dissatisfaction with leisure resource" had a higher ratio of those over 70s living in rural area. For them, leisure facilities and programs for relaxation and health need to be supplied. For example, Oh, Lee, \& Kim [38] segmented the clusters of leisure resources for senior citizens in a total of 31 administrative districts of Gyeonggi-do and then compared the result to Province development index of Gyeonggi-do. Since the cluster called "Unbalance of attitude and quality of life" had lower level of leisure time freedom, the accessibility to leisure facilities need to be secured. In case of the cluster called "Sensitivity to leisure constraints", they showed high leisure index but they perceived all leisure constraints at the same time. Therefore, giving support to address this problem is required as a way to cope with leisure constraints. Finally, the researchers suggested a way to improve leisure condition for senior citizens in the aspect of welfare based on the clusters resulted from the research. In the urban area, there are a lot of people living with diverse leisure index. This study can be a basis for the enabling relevant professionals to provide suitable leisure services for a particular target group.

\section{Conclusions}

In summary, results of this study and previous researches showed that there were definite differences among purposes of leisure, leisure constraints, and quality of life depending on leisure index. These differences were used to profile characteristics of each cluster. Such characteristics of each cluster including aspects of leisure, regional size, and socio-demographic characteristics could be used as baseline data to develop a policy for leisure sustainability. The three different clusters called "dissatisfaction with leisure resource", "dissatisfaction with the quality of life", and "sensitive to the leisure constraints" in the study represent different needs for sustainable leisure services and higher quality of life. Thus, the specific direction of the policy to this end should be support for leisure facilities, work-life balance, and negotiations on leisure constraints considering the characteristics of each cluster. Meanwhile, the leisure index is becoming an international standard for measure happiness. This study using the leisure index developed in Korea will contribute to increasing the academic value of leisure index. The leisure index used in this study can be helpful to analyze the leisure environment of individuals and specific regions. This can serve as an academic foundation for the activation of various subsequent researches regarding leisure index. The findings of this study suggest the direction of developing a practical policy plan of leisure for all and the academic value of leisure index.

Author Contributions: Conceptualization, J.K., S.O. and B.Y.; Methodology, J.K.; Formal analysis, J.K.; Writing-original draft preparation J.K., S.O. and B.Y.; Writing-review and editing, S.O and B.Y. All authors have read and agreed to the published version of the manuscript.

Funding: This research received no external funding.

Institutional Review Board Statement: Not applicable.

Informed Consent Statement: Not applicable.

Data Availability Statement: Not applicable.

Conflicts of Interest: The authors declare no conflict of interest. 


\section{References}

1. Bregman, R. Utopia for Realists: And How We Can Get There; Bloomsbury Publishing: London, UK, 2017.

2. Kim, K.-S.; Lee, R.-J. Leisure activities, leisure satisfaction and happiness among the korean: Utilizing data of national statistics. J. Korea Contents Assoc. 2011, 11, 424-433. [CrossRef]

3. Lee, M.; Hwang, S. Happiness as the leisure time increases?: An application of easterlin paradox to leisure studies. Korean J. Leis. Recreat. Park 2014, 38, 29-38.

4. OECD. How's Life? 2020 Measuring Well-Being; OECD: Paris, France, 2020.

5. Ministry of Culture and Sports. 2019 National Leisure Activities Survey; Ministry of Culture and Sports: Seoul, Korea, 2020.

6. Hur, T.; Park, C. Psychological analysis of leisure failures: Why and What? J. Leis. Stud. 2004, 2, 69-85.

7. Iyengar, S.S.; Wells, R.E.; Schwartz, B. Doing better but feeling worse: Looking for the "best" job undermines satisfaction. Psychol. Sci. 2006, 17, 143-150. [CrossRef]

8. Yoon, S. Development and Application of Leisure Happiness Index; Korea Culture and Tourism Institute: Seoul, Korea, 2019.

9. Henderson, K.A. Introduction to Recreation Services: Sustainability for A Changing World; Venture Publishing: State College, PA, USA, 2014.

10. Gimenez-Nadal, J.I.; Sevilla-Sanz, A. The time-crunch paradox. Soc. Indic. Res. 2011, 102, 181-196. [CrossRef]

11. Kim, B.; Paek, H.; Yang, M. Qualitative Content Analysis on Participation Constraints and Discontinuation Reasons for Horseback Riding among Horseback Riding Club Members of Jeju Province. Korean Soc. Leis. Recreat. 2016, 40, 48-68.

12. Yoon, C.; Park, S. An Exploration of Types of Leisure Consumption of Workers. J. Leis. Stud. 2018, 16, 67-97.

13. Lee, C. Qualitative inquiry for leisure constraint and leisure boredom in the lives of middle aged men. J. Leis. Recreat. Stud. 2014, $38,1-16$.

14. Mannell, R.C.; Kleiber, D.A. A Social Psychology of Leisure; Venture Publishing Inc.: Edmonton, AB, Canada, 1997.

15. Godbey, G.; Crawford, D.W.; Shen, X.S. Assessing hierarchical leisure constraints theory after two decades. J. Leis. Res. 2010, 42, 111-134. [CrossRef]

16. Heo, J. Satisfaction and Constraints on Leisure Activities Participation among the Leisure Facilities User in Korea. Korea Tour. Res. Assoc. 2014, 28, 203-213.

17. Hong, S.; Kim, S. Constraints to participation in senior welfare centers: Focusing on the difference of regional types. Health Soc. Welf. Rev. 2016, 36, 125-156. [CrossRef]

18. Shin, C.H.; Ha, S.K. Strategies for Building a Leisure City Brand to Vitalize the Leisure Industry. J. Leis. Stud. 2007, 5, 40-57.

19. Nam, Y.S. Evaluation of locational accessibility to leisure facilities using GIS: Focusing on Jeju city Dong area. Korean J. Leis. Precreat. Park 2019, 43, 69-80. [CrossRef]

20. Iso-Ahola, S. The Social Psychology of Leisure and Recreation; William, C. Brown Co. Publishing: Dubuque, IA, USA, 1980; 436p.

21. Manfredo, M.J.; Yuan, S.M.; McGuire, F.A. The influence of attitude accessibility on attitude-behavior relationships: Implications for recreation research. J. Leis. Res. 1992, 24, 157-170. [CrossRef]

22. Seligman, M.E.; Rashid, T.; Parks ACPeterson, C.; Seligman, M.E.P. Character Strengths and Virtues: A Handbook and Classification; American Psychological Association and Oxford University Press: Washington, DC, USA, 2004; Volume 51, pp. 1072-1079.

23. Haugland, S.; Wold, B.; Torsheim, T. Relieving the pressure? The role of physical activity in the relationship between school-related stress and adolescent health complaints. Res. Q. Exerc. Sport 2003, 74, 127-135. [CrossRef]

24. Zimbardo, P.; Boyd, J. The Time Paradox: The New Psychology of Time That Will Change Your Life; Simon and Schuster: New York, NY, USA, 2008.

25. Janssen, M.; Walravens, R.; Thibaut, E.; Scheerder, J.; Brombacher, A.; Vos, S. Understanding different types of recreational runners and how they use running-related technology. Int. J. Environ. Res. Public Health 2020, 17, 2276. [CrossRef] [PubMed]

26. Kim, J.S. A Segmentation through angling participants' recreation specialization and their enjoyment pattern analysis. Korean J. Leis. Recreat. Park 2017, 41, 27-38. [CrossRef]

27. Ryan, C.; Glendon, I. Application of leisure motivation scale to tourism. Ann. Touri. Res. 1998, 25, 169-184. [CrossRef]

28. Song, J. Statistical Analysis Method for SPSS/AMOS for the Preparation of the Paper; 21st Century Book: Seoul, Korea, 2008.

29. Bell, S.J.; Menguc, B. The employee-organization relationship, organizational citizenship behaviors, and superior service quality. J. Retail. 2002, 78, 131-146. [CrossRef]

30. Kim, M.; Ko, J. A Study on the Current Status of Sports Facility Composition Utilizing Idle Space and Overseas Cases. J. Korean Soc. Sport Policy 2016, 14, 85-100.

31. Ministry of Culture, Sports and Tourism. Public Sports Facilities Balanced Long-Term Deployment Plan; Ministry of Culture, Sports and Tourism: Seoul, Korea, 2014.

32. Weagley, R.O.; Huh, E. Leisure expenditures of retired and near-retired households. J. Leis. Res. 2004, 36, 101-127. [CrossRef]

33. Lee, N.; Zvonkovic, A.M.; Crawford, D.W. The impact of work-family conflict and facilitation on women's perceptions of role balance. J. Fam. Issues 2014, 35, 1252-1274. [CrossRef]

34. Lyu, S.O.; Oh, C.-O. Bridging the conceptual frameworks of constraints negotiation and serious leisure to understand leisure benefit realization. Leis. Sci. 2015, 37, 176-193. [CrossRef]

35. Park, J.; Son, Y.; Shin, K. The Effects of Social Support for Married Working Women to Work Life Balance. J. Korea Soc. Wellness 2016, 11, 69-81. [CrossRef] 
36. Park, J.-S.; Park, K.-R. The effects of leisure constraints and leisure sufficiency of late middle-aged adults on their life satisfaction. Korean J. Hum. Ecol. 2009, 18, 689-703. [CrossRef]

37. López-Mosquera, N.; Sánchez, M. Direct and indirect effects of received benefits and place attachment in willingness to pay and loyalty in suburban natural areas. J. Environ. Psychol. 2013, 34, 27-35. [CrossRef]

38. Oh, S.S.; Lee, J.S.; Kim, J.S. A Study on Regional Differentiation to Encourage Leisure Activities of the Elderly Residing in Gyeonggi Province. J. Leis. Stud. 2015, 13, 127-150. 